\title{
Bilateral microvascular second toe transfer for bilateral post-traumatic thumb amputation
}

\author{
Rajendra Nehete, Anita Nehete ${ }^{1}$, Sandeep Singla, Harshad Adhav ${ }^{2}$ \\ Department of Plastic Surgery, ${ }^{1}$ Department of Anaesthesiology, ${ }^{2}$ Department of Orthopaedics, Vedant (Nehete) Hospital, \\ Nashik, Maharashtra, India
}

Address for correspondence: Dr. Rajendra Y Nehete, Nehete Hospital, Shreehari Kute Marg, Near Mumbai Naka, Nashik - 422002 , Maharashtra, India. E-mail: rajendranehete@gmail.com

\section{ABSTRACT}

In bilateral thumb amputations, the functional impairment is serious and every attempt should be made to reconstruct the thumb. We report a case of bilateral post traumatic thumb amputation, reconstructed with bilateral second toe transfer. Only two such cases have been reported in literature so far. Though there are various modalities for the reconstruction of thumb, microvascular toe transfer has its own merits. The convalescent period is minimal with excellent function. It is bilaterally symmetric and aesthetically superior to the osteoplastic reconstruction. The technical details are discussed, and the long term functional and aesthetic results are presented.

\section{KEY WORDS}

Microvascular transfer; second toe; thumb amputation

\section{INTRODUCTION}

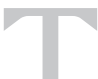

raumatic loss of thumb leads to significant loss of function as the thumb contributes to about $40 \%$ of the hand functions. ${ }^{[1]}$ When the loss is bilateral, it is more devastating. Replantation is indicated in all cases; however, may not be possible in cases with unsuitably amputated thumb. Toe to thumb transfer is an excellent option in these patients and helps restore both function and esthetics. ${ }^{[1-4]}$ We have performed a bilateral second toe to thumb transfer in a patient who underwent bilateral traumatic thumb amputation. Only two such cases have been reported in literature so far. ${ }^{[2]}$

\begin{tabular}{|l|l|}
\hline \multicolumn{2}{|c|}{ Access this article online } \\
\hline Quick Response Code: & Website: \\
\hline & www.ijps.org \\
\cline { 2 - 2 } & Dol: \\
\hline
\end{tabular}

Indian Journal of Plastic Surgery January-April 2012 Vol 45 Issue 1

\section{CASE REPORT}

A 25 year old male presented to our department with the traumatic amputation of both the thumbs distal to the metacarpophalangeal (MCP) joint, and at the proximal $1 / 3^{\text {rd }}$ of the proximal phalanx while working on punch press machine [Figure 1]. The amputated parts were not replantable. After discussing the pros and cons of the different modalities of reconstruction, a decision to perform the bilateral second toe transfer was taken. Within 12 hours of the injury, the left second toe was transferred to the right thumb. A week later, the right second toe was transferred to left thumb.

\section{Anesthesia administered}

Surgery was performed under the combination of spinal, epidural and brachial blocks, and was supplemented with intravenous general anaesthesia.

\section{Dissection of the toe}

The dorsal pedis artery and dorsal superficial veins were 


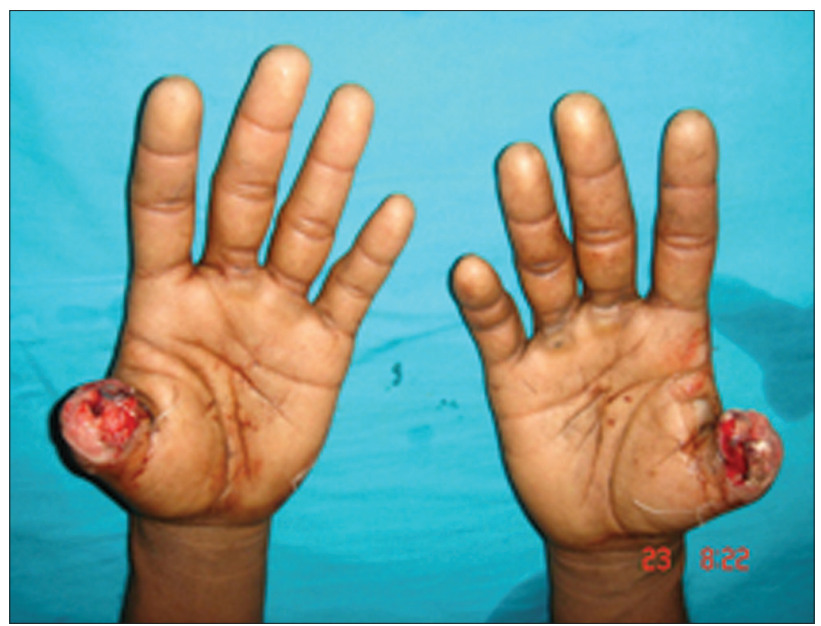

Figure 1: Preoperative view of amputated bilateral thumbs

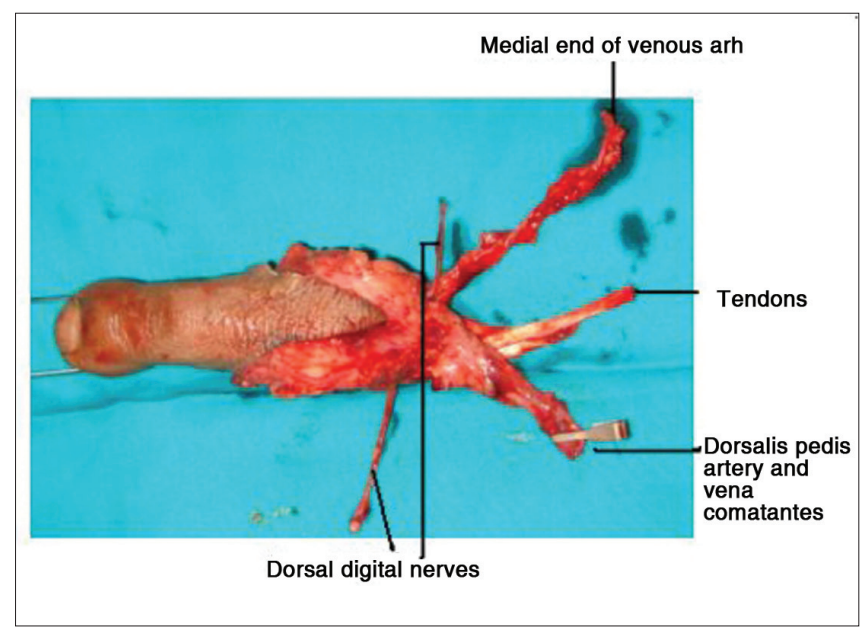

Figure 3: Dorsal View of harvested second toe

marked. A tourniquet was raised. A ' $\mathrm{V}$ ' shaped incision was taken at the base of the second toe and extended proximally. Superficial dorsal veins were dissected. The first dorsal metacarpal artery (FDMA) was seen dorsal to the dorsal interosseous muscle, and dissected proximally. The slip of extensor digitorum longus (EDL) and the deep peroneal and dorsal digital nerves, were dissected proximally. The plantar dissection was started by taking 'a V' shaped incision extending proximally up to the instep area. Plantar digital arteries and nerves were identified and proximal intraneural dissection was done. The Flexor Hallucis Longus (FHL) tendon was dissected proximally for adequate length. Disarticulation was done at second metatarsophalangeal (MTP) joint. Vascularity to the toe was confirmed after the release of tourniquet.

\section{Recipient site dissection}

At this stage, the brachial block was given. Two incisions were taken. Through the dorsoulnar incision, the dorsal

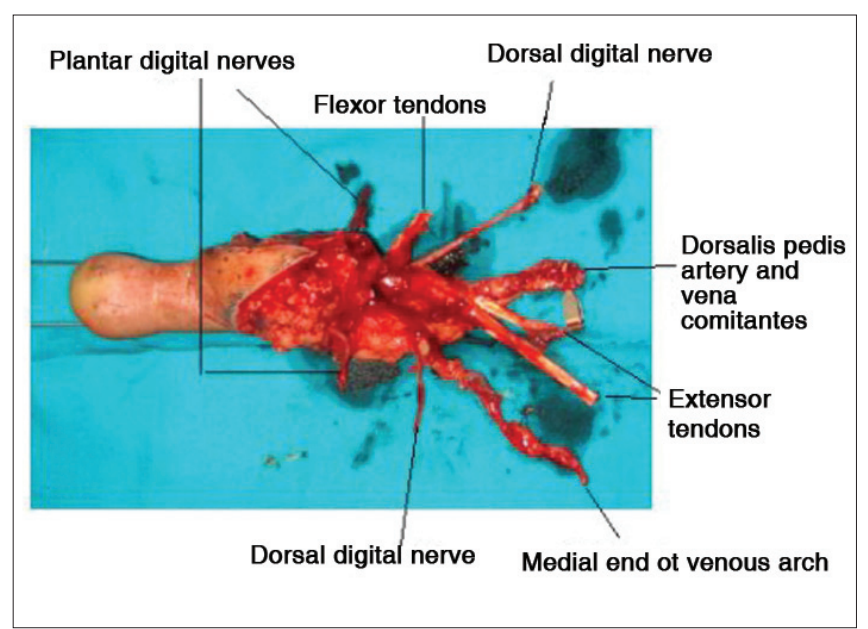

Figure 2: Plantar view of harvested second toe

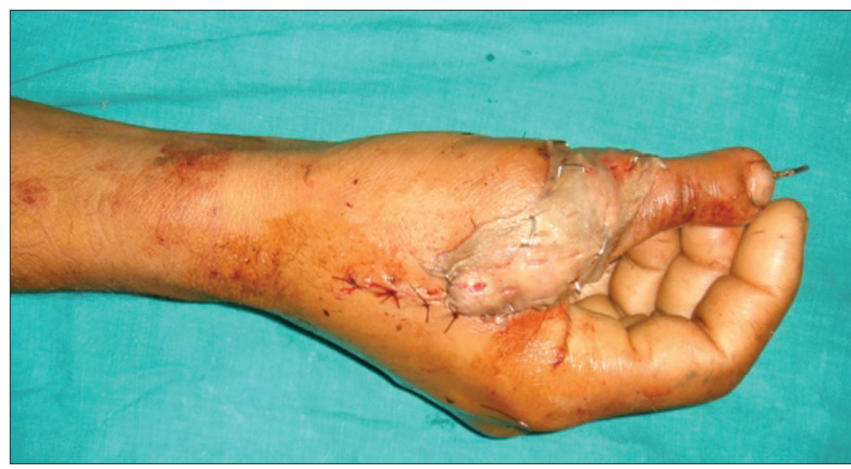

Figure 4: Intraoperative view of second toe transferred to thumb. Also seen the grafted the area to avoid wound closure with undue tension

branch of the radial artery, its venae comitantes, tributary of cephalic vein, the dorsal digital nerve and the proximal end of the extensor pollicis longus (EPL) were explored and tagged. Through volar incision, flexor pollicis longus (FPL) proximal end and digital nerves were explored. The bony stump was freshened.

\section{Transfer of toe}

The toe was separated by ligating the pedicle and transferred to recipient site [Figure 2 and 3]. After removing the articular surface of donor toe proximal phalanx, osteosynthesis was done using axial $\mathrm{k}$ wire and interosseous wiring. Flexor and extensor tendons were repaired [Flexor Digitorum Longus (FDL) to FPL, extensor digitorum longus (EDL) to EPL]. Bilateral plantar digital nerves were coapted to volar digital nerves of the thumb, and the dorsal digital nerve was coapted to the dorsal digital nerve of thumb. The Medial arch vein and venae comitantes of donor toe were anastomosed with a tributary of cephalic vein and venae comitantes of the radial artery, respectively. Vascularity of the toe was confirmed. Wounds were closed without undue tension. 
Table 1: Functional assessment of the patient in the reported case study with bilateral second toe to thumb transfer, at follow up at the end of $1,2 \& 3$ years

\begin{tabular}{|c|c|c|c|c|c|c|}
\hline \multirow[t]{2}{*}{ Function } & \multicolumn{3}{|c|}{ Right hand } & \multicolumn{3}{|c|}{ Left hand } \\
\hline & 1 year & 2 years & 3 years & 1 year & 2 years & 3 years \\
\hline Static two point discrimination $(\mathrm{mm})$ & $12 \mathrm{~mm}$ & $8 \mathrm{~mm}$ & $8 \mathrm{~mm}$ & $13 \mathrm{~mm}$ & $9 \mathrm{~mm}$ & $8 \mathrm{~mm}$ \\
\hline Key pinch strength (Normal 6-9 kgf) & 6 & 0 & 7 & 4 & 5 & 6 \\
\hline Grip strength (Normal 40-45 kgf) & 34 & 40 & 40 & 34 & 38 & 38 \\
\hline \multicolumn{7}{|l|}{ Active flexion(in degrees) } \\
\hline IP joint & 60 & 60 & 60 & 10 & 10 & 10 \\
\hline MCP joint & 60 & 60 & 60 & 40 & 40 & 40 \\
\hline Hyperextension(in degrees) MCP joint & 10 & 10 & 10 & 20 & 20 & 20 \\
\hline
\end{tabular}

Where, IP = Interphalangeal; MCP = Metacarpophalangeal

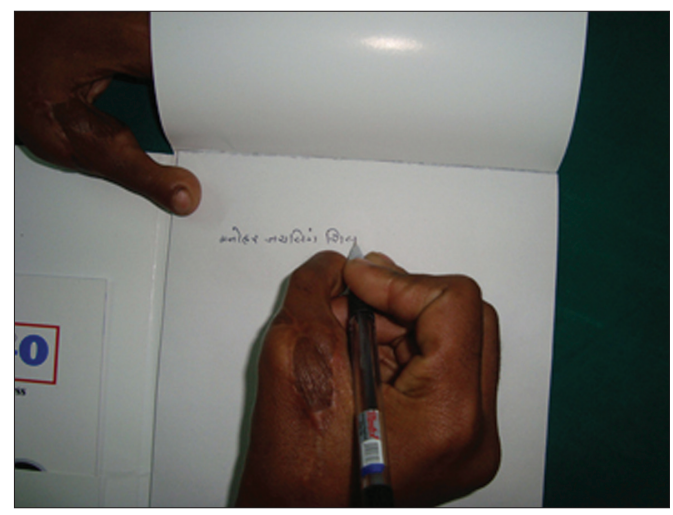

Figure 5: Good function achieved after toe transfer

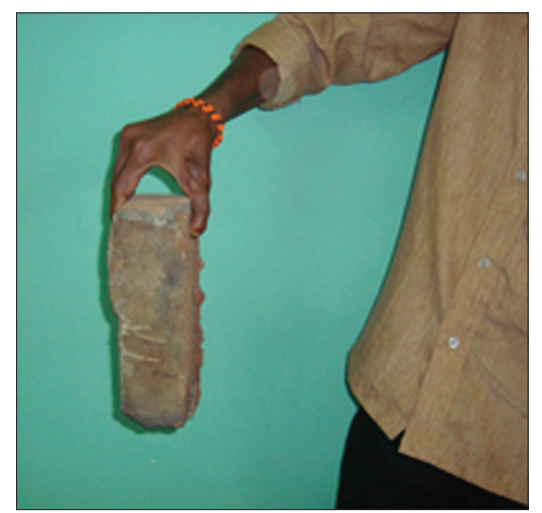

Figure 6: Excellet strength achieved after toe transfer(right thumb)

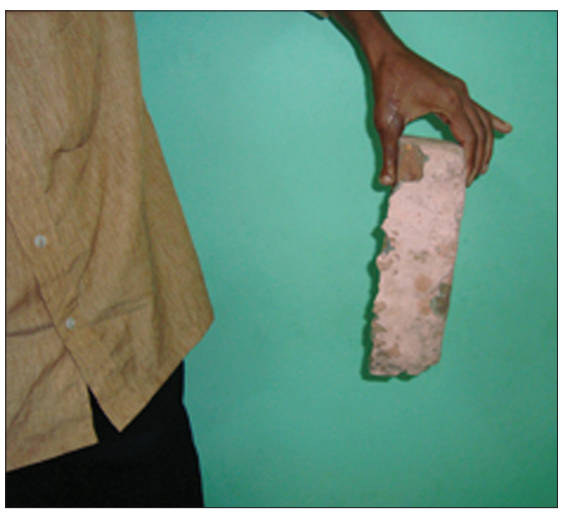

Figure 7: Excellent strength achieved after toe transfer (left thumb)

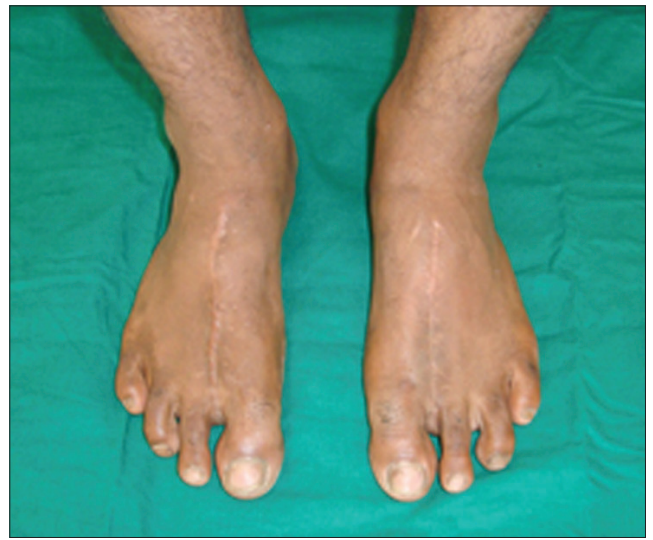

Figure 8: Minimal donor side morbidity which goes unnoticed

Residual raw areas on the radial and ulnar aspect of the reconstructed thumb were grafted [Figure 4].

\section{Closure of donor area}

The second metatarsal was shortened. The gap between the first and third toe was reduced by repair of intermetatarsal ligament and transverse $\mathrm{K}$ wire. Wounds were closed after putting a suction drain. A similar procedure was carried out for the reconstruction of the left thumb using the right second toe. In the right Indian Journal of Plastic Surgery January-April 2012 Vol 45 Issue 1

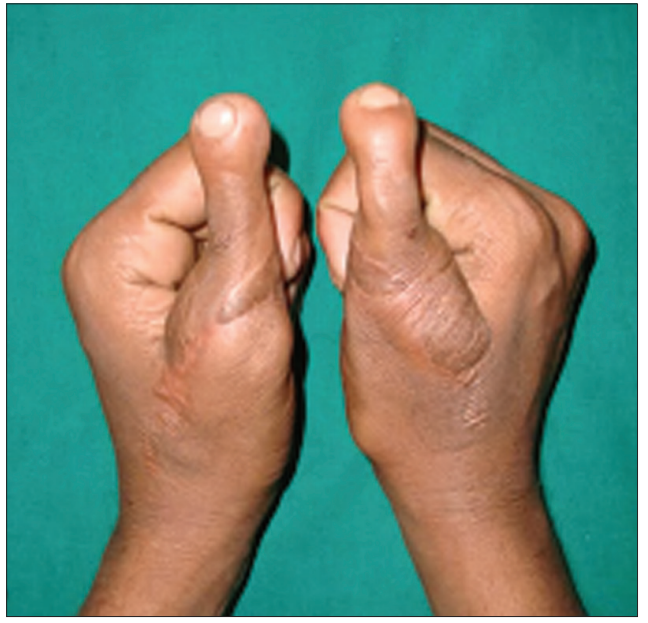

Figure 9: Excellent strength achieved after toe transfer

foot, FDMA was plantar dominant. Rehabilitation: After 3weeks, the $\mathrm{K}$ wires were removed, and the patient was supervised daily. Physiotherapy in the form of active flexion and extension was started and continued for 2 months. Weight bearing and ambulation was also resumed at the same time. The sensory re-education and rehabilitation was continued for 8 months. Patient had a recovery of protective sensation at 8 months, and was advised to resume his normal duties. Functional 
assessment at follow up at the end of $1,2 \& 3$ years is shown in Table 1, and in Figures 5-7. The patient is back to the same occupation, \& has no disability or restricted flexion in terminal joint on the left sside; hence no further surgery has been carried out.

\section{DISCUSSION}

Reconstruction of the thumb requires careful evaluation and discussion of the patient's occupational and social profile, and the treatment options available. Microvascular toe transfer has become an invaluable tool to restore hand function in such patients. It provides all components necessary for good thumb function. The advantage of second toe transfer is minimal donor site morbidity, excellent appearance and good function, making it the preferred digit for use for thumb transfer. ${ }^{[3]}$ However, it is important to consider this in the Indian population as many here people walk barefoot or wear chappels. In our case, after discussing all the reconstructive options, a decision to perform a bilateral second toe transfer was taken. The surgery is of long duration, and also places significant physiological demands on the patient, and hence was performed in two stages. A gap of one week was maintained between the two stages. This was done to ensure the definitive survival of the transferred toe, and also as we do not expect any vascular event beyond one week. During the second surgery as well, the pedicle dissection has to done carefully, as the course of the FDMA may be different here and not necessarily similar to the first surgery. ${ }^{[5,6]}$ Also, precautions need to be taken to maintain the proper tensioning of the tendons, and from an esthetic point of view, the same length of the reconstructed thumbs needs to be maintained on both the sides. We had a long term follow up (defined as $>3$ years) for the patient, as by this time the neural recovery is almost complete, and most of the adaptation to the newly reconstructed thumb has occurred. In our case, patient resumed his previous job without any difficulity. ${ }^{[7]}$

Thus to conclude, bilateral second toe to thumb microvascular transfer restores excellent hand function with minimal morbidity in the foot [Figure 8]. Primary toe transfer, not only decreases the convalescent period and the medical costs, but also ensures early return to work. $^{[2,8]}$ Besides, it gives bilaterally symmetrical and aesthetically pleasing thumbs [Figure 9].

\section{REFERENCES}

1. Chung KC, Wei FC. An outcome study of thumb reconstruction using microvascular toe transfer. J Hand Surg Am 2000;25: 651-8.

2. Xu L, Gu YD, Xu JG, Rui YJ, Shou KS. Microsurgical treatment for bilateral thumb defect. Five case reports. Microsurgery 2003;23:547-54.

3. Vedder NB, Master BM. Thumb Reconstruction; Microvascular Methods. In: Mathes SJ, Hentz VR, eds. Plastic Surgery. $2^{\text {nd }}$ ed. Philadelphia: Elsevier; 2006. p. 253-80.

4. Sabapathy SR, Venkatramani H, Bharathi RR. Functional evaluation of great toe transfer and the osteoplastic technique for thumb reconstruction in the same individual. J Hand Surg $\mathrm{Br}$ 2003;28:405-8.

5. Gu YD, Zhang GM, Chen DS, Cheng XM, Xu JG, Wang $H$. Vascular anatomic variations in second toe transfers. J Hand Surg Am 2000;25:277-81.

6. Leung PC, Wong WL. The vessels of the first metatarsal web space. An operative and radiographic study. J Bone Joint Surg Am 1983;65:235-8.

7. Kotkansalo T, Vilkki S, Elo P, Luukkaala T. Long-term functional results of microvascular toe-to-thumb reconstruction. J Hand Surg Eur 2011;36:194-204.

8. Woo SH, Kim JS, Seul JH. Immediate Toe to Hand transfer in Acute Hand Injuries: Overall Results, Compared With results for Elective Cases. Plast Reconstr Surg 2004;113:882-92.

How to cite this article: Nehete R, Nehete A, Singla S, Adhav H. Bilateral microvascular second toe transfer for bilateral post-traumatic thumb amputation. Indian J Plast Surg 2012;45:154-7.

Source of Support: Nil, Conflict of Interest: None declared. 